
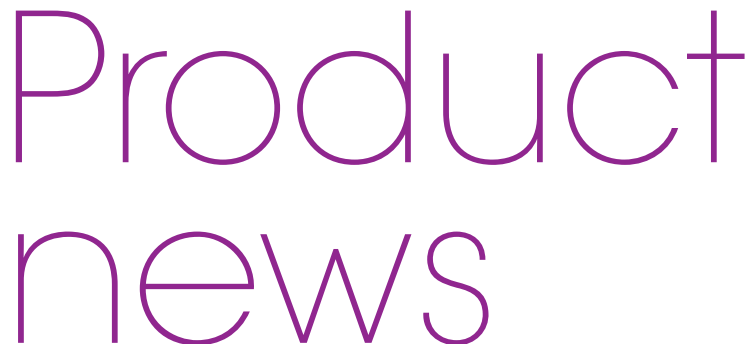

\section{BICKIEPEGS SUPPORTS POSTERS FOR DENTAL PRACTICES}

In support of the BSPD's \#DCbyl (Dental Check by One Campaign) dentists are being encouraged to remind parents that NHS dental checks for children are free in England and the recommendation is to get all babies into the dentist's chair before their first birthday.

The Office of the Chief Dental Officer, England, has created new attentiongrabbing public awareness posters using a "Little Monsters" theme. This is in support of BSPD's DCbyl campaign. Bickiepegs Healthcare, experts in baby oral health for over 90 years, have joined with the OCDO team to print and distribute 500 posters to dental practices in the South of England.

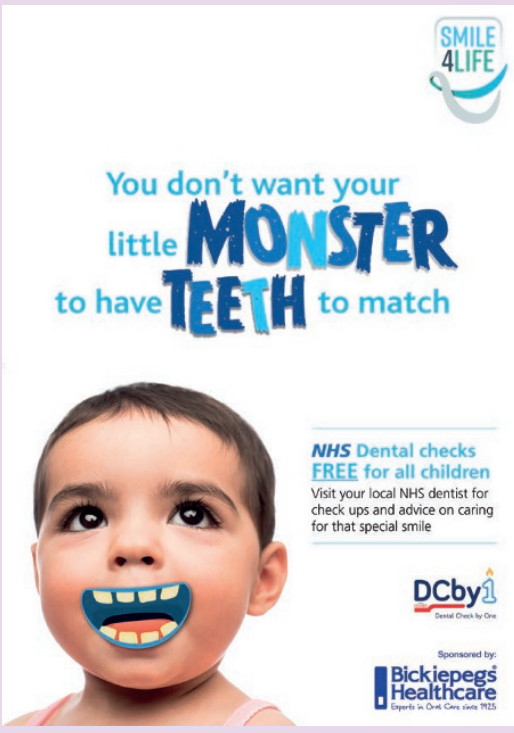

\title{
RADIOLOGY SOLUTION - UPGRADE WITH PROPACS
}

PROPACS from PRO Diagnostics UK is the perfect solution to seamlessly and quickly manage your diagnostic imaging workflow with the touch of a button. PROPACS automatically stores a copy of your diagnostic image library within the UK.

The system also has a unique dental radiology reporting service. In just 24 hours, your radiographs could be analysed by dedicated dental radiology specialists, saving you time and ensuring that you have all the necessary information you need to create an effective care plan for your patient.

The benefits of PROPACS are that you:

- Save time on radiology reporting.

- Lower your medical legal liability.

- Comply to the recently upgraded GDPR requirements!

For more information, please visit www. prodentalradiology.com or email sales@ prodiagnostics.co.uk
TIME TO REJUVENATE YOUR PATIENT

\section{DENTAL CHAIRS?}

Meditelle-Dental provides a specialised onsite service to re-upholster all brands and models of patient dental chairs, across the UK.

To ensure your equipment is not out of service for any length of time and to minimise downtime all procedures are carried out at your surgery, so you can get a fresh new look for your dental chairs in just a few hours. Our visiting expert upholsterer has over 20 years' upholstering experience, so you can be assured of a professional finish.

Re-upholstering your patient chairs may be all that's required if you have any scuffs, slits or tears in your dental chair vinyl that could present an infection control risk. Meditelle's re-covering service will ensure that your patient chairs are hygienic and the safety of your equipment is maintained in line with CQC requirements.

Meditelle offers you a wide range of over 20 vinyl colours to choose from, all are medical contract grade vinyl's and contain an antimicrobial additive to provide long-lasting effectiveness even after regular cleaning. They are also effective against the spread of MRSA, E coli and other bacteria on its surface.

At the same visit you can also have a 'made-to-measure' scuff guard fitted to your newly upholstered dental chairs and opt to have your operator seating recovered in the same matching vinyl.

Flexible onsite appointments are availble to work around your practice's busy schedule with early time slots prior to opening.

Obtaining a no-obligation quotation couldn't be easier, just email Meditelle a full image of your chair front and back along with your postcode location. For more information, www.meditelle-dental.co.uk

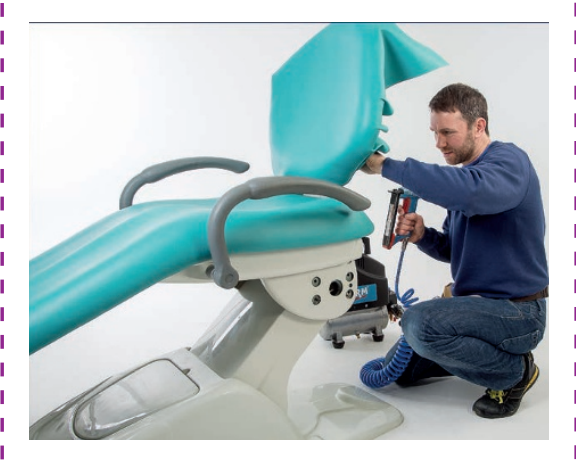

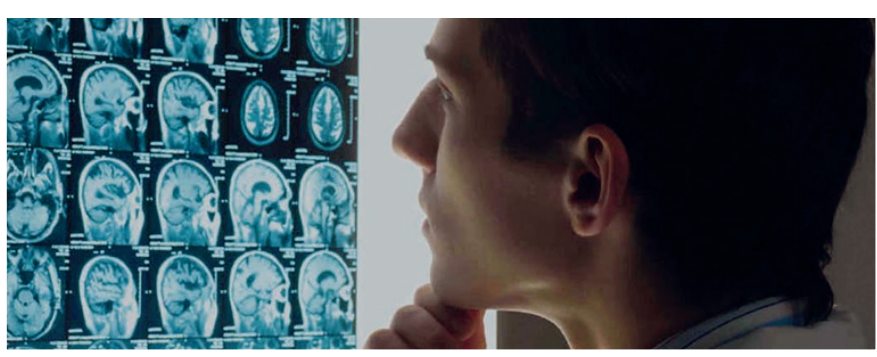

